\title{
There is No Tail without the Head: The Missing Pieces, the Alignment and the Training Returns through Training Need Assessment
}

Hanif Mohammed*

Da Vinci Trainers and Consultants, Karachi, Pakistan

\begin{abstract}
When the management thinks of results normal perception is that the training events will improve employee performance. Without knowing the target is like shooting an arrow in the dark hoping that might hit the mark. Organizations' normal protocol to conduct TNA is while going through employee performance appraisal. However, TNA provides broader aspects to seeing the performance gaps and resource channelization. TNA serves organizations in several ways which might provide input into training design, base line data for evaluation, assess the gaps in performance, competency levels of individuals etc. Evaluation models rely on TNA to be able to gain the results of training or create an impact. The missing person in any stage of training is the immediate supervisor who is hardly consulted in developing the training, the contents of the training or while s/he is supposed to reinforce the learning in the requisite job. This paper highlights the missing pieces and aligning the TNA to Training Evaluation.
\end{abstract}

Keywords: Training need assessment; Baseline data; Kirkpatrick model; Training evaluation; Organizational performance; Performance gaps; Training design

\section{Introduction}

Organizations and executives hoping to reap the results of the training investment need to understand that result is always at the end of a systematic approach where resources are allocated in this process from head to tail (the beginning till the end). Given any evaluation model the first step is always need identification.

Any efforts put in for the training is to improve the performance of the individual, department or the organization. Whereas, the same question is raised by the top management, unknown from the results, on return of training investment at the beginning of every budgetary cycle.

Brinkerhoff [1], Mooney and Brinkerhoff [2] highlighted training transfer on the job to be between $5 \%$ and $20 \%$. Fitzpatrick [3] supported same statistics and came to the conclusion that application of the learning does not exceed $20 \%$.

Organizations use an unstructured, unsystematic and informal approach to conducting Training Need Assessment (TNA) relying heavily on top management judgment. Som and Nam [4] writes in his paper. He says normally training needs data comes to L\&OD and/or HR in a section given in performance appraisal filled by individuals themselves or by the supervisor of the individual, focusing more on the wants rather than the needs of business. Based on the performance appraisal feedback on development the Personal Development Plan (PDP) is developed.

Supervisor's dilemma is to send the individuals who are doing a good job (as a part of their incentive for doing a good) or to send the individuals who are weak in particular competence. Normally high performers are the ones going for training for their motivation and reward. The weaker competence individuals stay in the cycle where business needs improvement catering more to wants rather than need. These wants are not business specific rather a mere wish list.

Robinson [5] revealed that in 1975 the return of the training was only $15 \%$. Same study carried out in 2005 and a comparative analysis was carried out to the study of 1975 revealed no improvement in the result; the return in 2005 was still $15 \%$ of overall trainings conducted.

\section{Purpose of the Study}

There are very few studies carried out on TNA which entails on the systematic approach to aligning the chain of steps to reaching the business results this was emphasized by Arthur et al. [6]. Arthur et al. [6] further elaborated that there are handful of studies that shows the importance of research on TNA and not enough; hence this paper addresses the issues.

Organizations rely on performance appraisal forms is commonly used tool to address training needs through weaknesses which are biased writes Agnaia [7] and does not provide the right picture. The missing links to aligning TNA to training effectiveness is not seen in any paper yet and this paper highlights the importance of it.

This paper also highlights the areas that are still missing from the parts of TNA which carries a substantial contribution to the results of training. An example can be seen through TNA and training design issues. Post training supervisor's continuous support.

\section{Executive Concerns}

Phillips [8] in his article shows that CEOs do not get the value they need from the investment they do on the trainings of the staff. Pointing the concerns, he also mentioned that the CEOs expect the results in terms of return, impact or business alignment from trainings (defined as the tail in this paper) rather than inputs giving example to no. of people trained.

Phillips [8] further elaborates that there is very little evidence to prove the substantiality of training giving statistical details in his paper which are as follows:

${ }^{*}$ Corresponding author: Hanif Mohammed, Lead Trainer and Consultant, Da Vinci Trainers and Consultants, Karachi, PO Box 75950, Pakistan, Tel: 03002139625; E-mail: hanif.mohammed@gmail.com

Recieved March 20, 2018; Accepted May 08, 2018; Published May 16, 2018

Citation: Mohammed H (2018) There is No Tail without the Head: The Missing Pieces, the Alignment and the Training Returns through Training Need Assessment. J Entrepren Organiz Manag 7: 236. doi: 10.4172/2169-026X.1000236

Copyright: (๑) 2018 Mohammed $\mathrm{H}$. This is an open-access article distributed under the terms of the Creative Commons Attribution License, which permits unrestricted use, distribution, and reproduction in any medium, provided the original author and source are credited. 
1. $96 \%$ CEO would like to see the results of the training investment.

2. Only $8 \%$ of the executives see some evidence.

3. $74 \%$ of CEO and top management wanted to see ROI on their training investment.

4. Only $4 \%$ see the data presented to them showing results.

5. $64 \%$ of the executives are interested in application of learning which might include change in behavior, use of skills, use of technology etc.

6. Only $11 \%$ actually see the learning being converted into actual application.

7. Only $22 \%$ of the L\&OD has learning scorecards.

Management can only see data presented in-terms of input which includes no. of people; no. of hours spent and cost involved which does not show results in-terms of value. The CEOs in Dr. Phillips survey used terms like business alignment, business contribution and business value through learning which is not reported through L\&OD efforts.

The terms used by CEOs and Management teams refers to achieving business results in aligning HR future business skills requirement and developing the resource accordingly. Business contribution is referred to asset allocation on training and its returns. Business value refers to creating value addition for the business post training. Since data is not collected on outputs, outcomes or impact it is always a question to justify training budget to investment decisions (Figure 1).

Need is defined in training of the gap between the current performance and desired performance. The gap is of competency, skills, Behavior, knowledge or attitude that can be filled by developing desired abilities through training. Gupta [9] defines need assessment as follows:

"Needs assessment is a process for figuring out how to close a learning or performance gap. It involves determining what the important needs are and how to address them. The process includes comparing the current condition to the desired condition, defining the problem or problems, understanding the behaviors and mechanisms that contribute to the current condition, determining if and how specific behaviors and mechanisms can be changed to produce the desired condition, developing solution strategies, and building support for action".

The above definition draws attention to priority of needs for the business and addressing those needs. Identifying existing knowledge and knowledge that is required to perform a particular job. TNA also provides an understanding of behaviors which are currently existing and the desired behaviors. The relationship is bridging the gap between current situations to desired situation leading to creating an impact in business value addition.

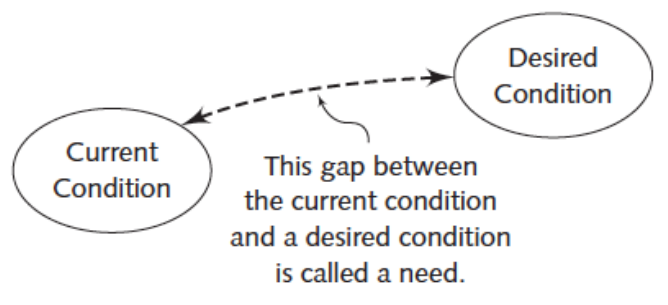

Figure 1: Understanding needs.

\section{Benefits of TNA}

Training Need Assessment not only helps in identifying performance gaps but it helps organizations in:

1. Identify the gap between current and required levels of knowledge, skills and aptitude. L\&OD departments while collecting the data on TNA can also identify the reasons for nonperformance be it knowledge, skills and aptitude or is it due to other organizational factors.

2. Defines general contents and design of the training while aiding in the development of the course.

3. Since organizations form an annual plan expanded towards the tenure of the training. TNA helps in the formation of annual training plan.

4. Channelization of budget towards the most important and priority based skills. TNA can also aid in understanding which trainings are important for which department and which trainings are priority (in terms of time). This can help in targeting the right training at the right time.

5. Provide a baseline for the evaluation of a training plan. When pre-training data is collected it also helps to compare posttraining evaluation on the changes occurring in performance or behavior.

6. Ensure that appropriate and relevant training is delivered. We can differentiate between needs and wants and this can help in identifying the needs of the business.

7. Maximize use of scarce resources. Resource allocation can be done to the most important aspects of development rather unknown factors and risking the investment not knowing how it will help post-developmental intervention.

8. Avoiding a past or current problem. TNA helps in developing a solution which might help in current problems that the organization is facing or the problems that has taken place in the past.

9. Creating or taking advantage of a future opportunity. Human resource development while looking at the future skills need can be addressed by TNA to understand how the business might change and in response how the HR needs to be trained.

10. Providing learning, development, or growth and competitive advantage. Bersin [10] writes in his article that internal learning and collaboration engraved in companies helps them to drive innovation and this helps them organizations to grow. These companies invest heavily on deep expertise development. Their HR then drives development, collaboration and share knowledge among themselves which is their prime factors for growth.

11. Helps in achieving competitive advantage through Human Development.

\section{Training Need Assessment and Business Results}

Sometimes training takes place by default in organizations as part of HR function irrespective if there is a need or not Taylor and O'Driscoll [11] point out in their study that for the past three decades there management has been concerned regarding taking training decisions randomly without a systematic approach. 
The first step in carrying out any training and development program is need assessment emphasizes Miller [12] and Dakiya and Jha [13]. They further elaborated that TNA provides the foundation for:

1. Writing Instructional objectives.

2. The selection and design of instructional programs.

3. The implementation of the program.

4. The evaluation of the training provided.

Skillnet [14] in their research write unless TNA is thoroughly and genuinely carried out it does not add value in any step to reap business impact. TNA provides the baseline data to have inputs in developing the requisite frame-work. These inputs pave the pathway to achieving desired results. These links are discussed below:

\section{TNA aids in training design}

While evaluating the needs for business TNA collects data on knowledge, abilities and behavioral gaps (KSA) for an individual that are then to be addressed by training. This data is applicable in two ways a) the collected data provides a baseline to design contents and context for training and b) pre-training data to compare with post-training improvement in KSA.

While the structure of the training is carried out a decision is taken on the type of activities that will be carried out on asynchronous or synchronous basis. It also aids in the design of instructions needed as Goldstein [15] described.

Without the data the training is merely an activity not seen as an investment for the business enhancement but an expense as it does not address required KSA to perform expected task or behavior modification.

In their research Eramus et al. [16] describes that needs identified helps in writing measurable training objectives; it also helps in guiding the process of training. The measurable objectives help in gauging post training evaluation. Supporting Eramus et al. [16], Molenda et al. [17] and Van Dyke et al. [18] explain the objectives in terms of what the participants will be able to do in a behavioral based training emphasizing on the quality of those behaviors as well as circumstances under which these behaviors will be demonstrated.

\section{TNA and targeting types of trainings}

Once the data is collected on types of trainings requested by the departments of an organization the compiled data shows the trainings mostly requested by each department. This can provide data on both liquid competencies (soft skills) and solid competencies (functional skills). The priority of training is set accordingly. TNA data can also shed light on the number of participants going through the training in a given time period, the departments requesting most of the trainings and the department's request least trainings. The substantiality of training each year provides a comparative analysis on time series whether particular trainings are requested repeatedly year after year is adding value or not. If the similar trainings are requested by similar departments over a period of time is indicative of a red flag on the learnings taking place and training substantiality in the evaluation process.

\section{Make or buy decision for cost effectiveness}

TNA data compiled and analyzed provides information on No. of employees needing similar trainings. It helps the management to decide which is more cost effective to outsource the training offered by different vendors as open generalized programs to cater to the needs or to offer it in-house while customizing the solution. A dilemma here is for the management to have cost savings or have specific solution to cater to the needs of the business. Searching for the right solution with external vendors is time consuming while matching the solution to the needs. For the right solution to match the training intervention Tung-Chun [19], recommends that the training be tailored to the organizational needs to have expected results.

\section{Business Needs and Evaluation Models}

One of the substantial models used in organizations to evaluate training effectiveness is Kirkpatrick [20] and Ellis (Figure 2) [21]. The first step described in Kirkpatrick Model is the identification of Business Needs. Kirkpatrick [22] explains four levels of data collection before the design of the training, implementation and evaluation. This data collection is done backwards from business results to training reaction. This base line data is collected backwards during TNA to compare pre and post training evaluation (Level 4 to Level 1) which is described below:

1. Business Results (L4): Taken in the form of performance; be it productivity, error rate, delays in process or customer complaints it is attributable to business performance where improvement is requirement. This data provides evidence on the problems, its severity and number of occurrences. This is then converted in monetary value to be able to check the magnitude of losses the organization is bearing.

2. Behaviors (L3): In this section data is collected on employee behaviors which are driving certain problems due to which L4 is occurring. It provides aid in training design on how much of behavior modification is required. The training is then designed to provide learning experiences to bring behaviors at par to the benchmarks. An example here could be what kind of leadership behavior can inspire employee.

3. Learning (L2): Cosh et al. [23] argue that organizational performance improvement depends on its ability to enhance knowledge, skills and attitudes. This is the area where KSA (knowledge, skills and attitudes) is reviewed. It is then used as a bridge to fill the gap between previous knowledge and expected knowledge. McClelland [24] and Ghufli [25] supporting the similar ideas emphasized on the organizational culture to be a contributory part for learning and enhancing organizational performance.

4. Reactions (L1): Kirkpatrick [22] further explains that an environment conducive to learning is an important factor. In L1 we need to see what kind of environment could promote learning. This is most commonly used method of training evaluation which only helps in understanding if the participants received the training appropriately while the objectives of the training were achieved from their perspective.

Kirkpatrick [22] defines these 4 Levels following a chain. Any step missing from this chain will not achieve the desired results. However, a program rated high does not guarantee learning.

\section{Participant's Immediate Supervisor's Missing Role}

In the above process an instrumental missing link that has not received much of popularity is the immediate supervisor. Immediate supervisor sees the errors, identifies improvements in behavior and 


\section{The Kirkpatrick Model}

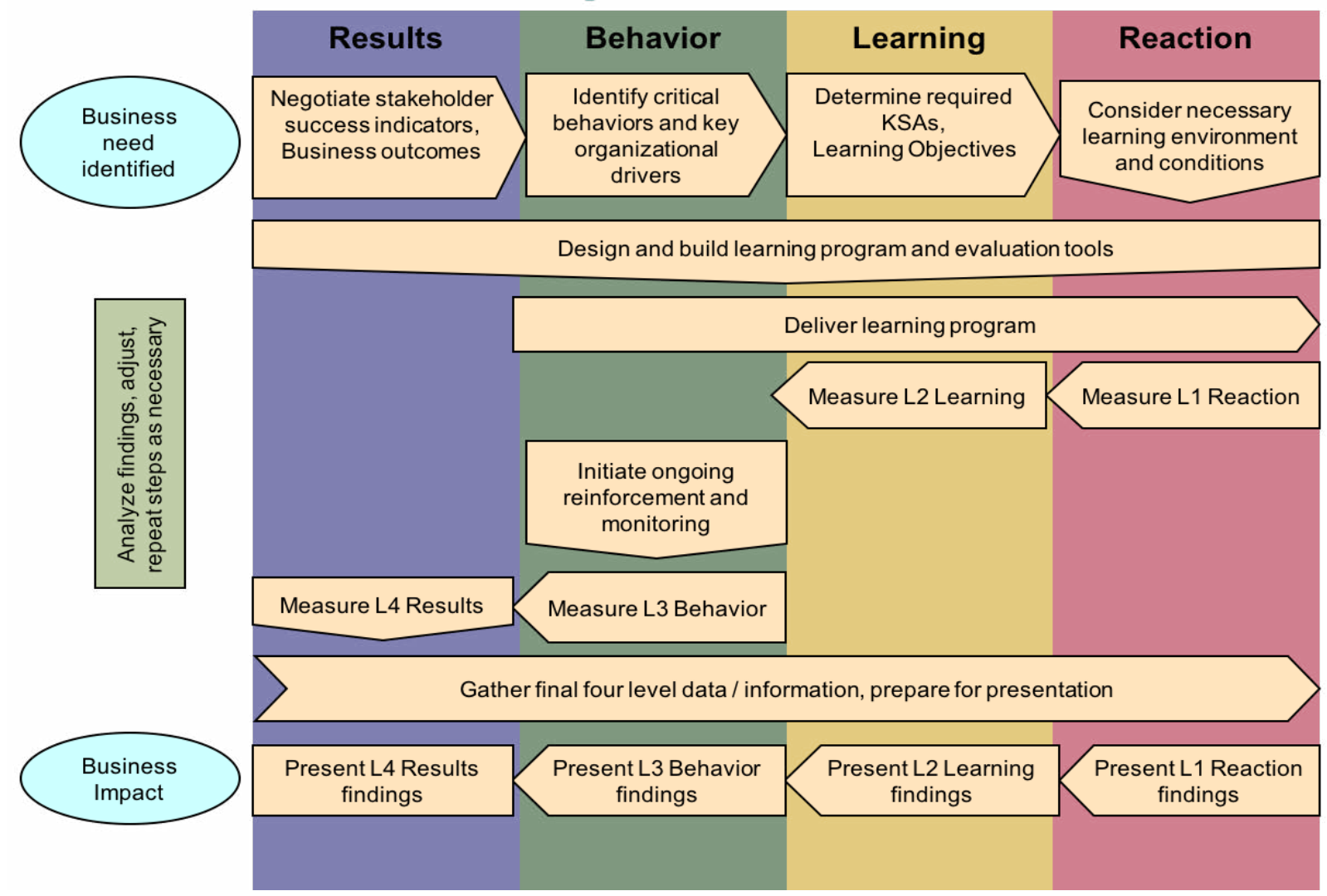

Figure 2: Training need assessment and Kirkpatrick model.

reinforces learning post training. Since he is the one managing the staff he is not involved in any step in any training process be it TNA or Evaluation processes. However, in Kirkpatrick [22] model he is only seen in the post training reinforcement scenario.

There has been now ample evidence which is indicative of how with supervisor's support organizations can reap greater returns on training investment. Cohen [26] in his study found that participants with supportive supervisors have strong belief that the training is useful and increases employee motivation. In researches conducted by Clark et al. [27] and Facteau et al. [28] similar results were seen supporting Cohen's [26] work where Clark [27] and his colleagues saw support from supervisor to reap better motivational levels of employees having application of post training learnings on job and reinforcement from supervisor to give improved organizational results.

Further extending to the same argument another study carried out by Farr and Middlebrooks [29] used Expectancy Theory to supervisors support for training motivation provided proof that supervisor's support positively influences participant's expectations. Supervisors' support influences individual motivation so much so that it far exceeds other variable like continuous learning culture. Employees perceive supervisor as a part of organizational culture supporting continuous learning write Chen et al. [30] and Tesluk et al. [31].

Winters and Latham [32] suggested in their paper the importance of involving the supervisors of the participants in pre-training stage early in the assessment to be able to have effectively received better results. Steven and Gist [33] also supported similar aspects of immediate supervisors' involvement early in the stages of training needs identification.

Supervisors can provide data pre-training while Training Need Assessment on all four levels L1 to L4. S/he also ensures learning implementation as well as reinforcing learned behaviors. At the end also gives feedback on post-training performance of participants (Figure 3).

McGriff [34] The ADDIE model is taken from ISD Model defines Branson et al. [35] containing normally five steps to provide a framework for Instructional Designers for the course design. The first step starts from analysis which covers extensive part on training needs assessment. Molenda et al. [17] and Treser [36] explain that need analysis defines the requirements before the Instructions are crafted which in turns creates the impact it will have on the return of the investment. Further Molenda et al. [17] added that designers need to identify measurable factors while drafting training objectives and then make sure these factors are quantified post training accordingly.

In the model above Need Analysis is the basis for ISD and at the core of both formative and summative evaluation. The links attribute to the factors that without the TNA evaluation becomes the most difficult one.

\section{Training Needs Analysis and Contents Design}

The trainers and management educators on the basis of Needs of business start to draft training objectives and defining the types of skills 


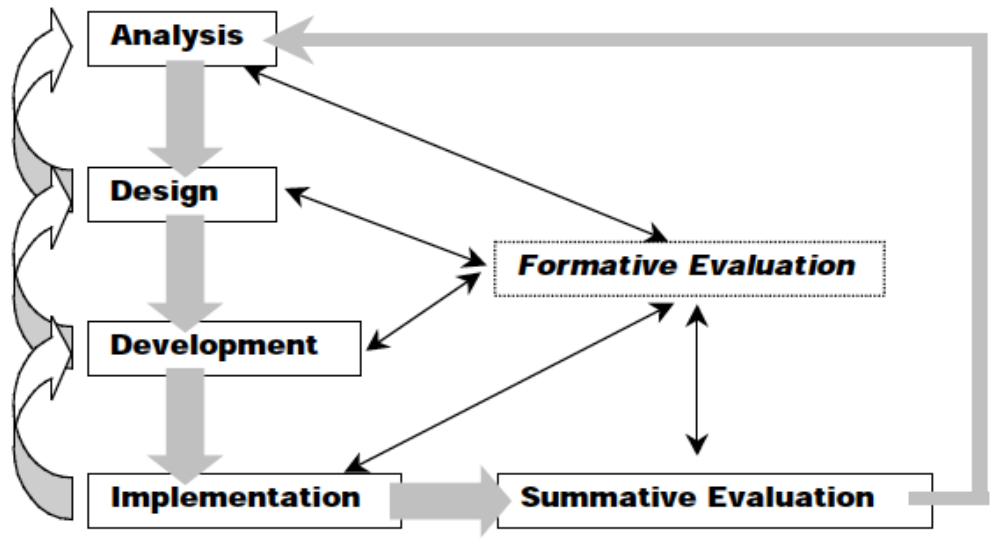

Figure 3: Training needs assessment and the Addie model

the training would address states Rossett [37] This knowledge, skills and attitudes are then defined through the areas that the training will address to solve business problems.

TNA addresses the severity of the problems and this helps in how much to cover for which areas. Bowen [38] states in his article Understanding by Design backward approach to designing training programs which starts from identifying desired results, determine acceptable evidence and then the last plan learning experiences and instruction.

The contents are then divided into three categories which includes the following:

1. Enduring Understanding

2. Important to know and do

3. Worth being familiar.

The first category is essential learning without which the participants will not be performing their jobs below par. The second category is important or essential to the job without which they can work but not effectively. The third category adds value to the job performance but not as much as the first two categories. It is good if the participants know. TNA provides the data on what to include in which type of category to improve the requisite performance. . The training blueprint is then prepared on how much time will be allocated to each content covering the depth and the breadth of the training.

\section{TNA and Trainer Selection}

While TNA helps in identifying training it also aids in recognizing trainer most suitable to develop the requisite skills in employees. Karen [39] in her book describes four different types of trainers:

1. The Seller: The seller type is normally more focus on how his training contents will be received by the participants. In their own thoughts learning is primarily the responsibility of the participants. They are more to be concerned with selling their own ideas.

2. The Professor: The professor type of trainers is focused to the details of the contents and their image in-front of the participants. The pay utmost attention to the techniques and creating an impression.

3. The Entertainer: Comparing entertainer with "Medicine-show
Huckster" Karen [39] describes that these type of trainers impress you with their talks and gimmicks that they take away your money and before you can judge the worth of the training they are already gone. They do not pay attention to skills development or the learning of the participants. They are more concerned with the enjoyment factor so much so that learning of skills here becomes secondary.

4. The Coach: The best category of trainers Karen defines is the coaches. These trainers facilitate learning. They pay attention to skills development and build confidence in participants while focusing on application of learning. Coaches evaluate the participants through their observations in the classroom for performance and behavioral change.

Felder and Brent [40] provided evidence on three variables interlinked to achieve the desired results. Suggesting a framework of cognitive taxonomical basis provided by Bloom [41] Felder and Brent [42] suggested writing educational objectives as the driving force to achieve the desired results.

The second step suggested by Felder and Brent [40] is to write instructions to achieve the objectives and the third step is to assess performance of the participants based on the learning objectives laid down in the first step. To have the desired performance from the participants if any of the links is missing will break the strings and the results will not be achieved as expected from the objectives. Organizations investing in trainings have a disconnect between what is the design of the training, the learning objectives, and what is to be delivered in the training room. The trainer selection provides instructions in the learning process while in contact with the participants.

The classroom is solely left to the trainer and L\&OD department cannot know what has happened in the classroom. The skills development if not carried out and an entertainer is hired chances are participants might enjoy the training in the presence of entertainment but learning appropriate skills will still be missing.

The disconnection between the design of the training and the trainer may result in not achieving the objectives of the course. Hence expected return on the training investment by the organization may hinder creating problems in L2, L3 and L4 of training evaluation process. 


\section{Aligning Training Need Assessment to Evaluation}

Aligning TNA to training Evaluation provides feedback to executives in making investment decisions. TNA reveals the data on training repeatedly arising from departments shows comparative on time series giving details of requirements, however, evaluation provides data on the training effectiveness showing which trainings are to be carried out and where the investment is worth spending. The data not available can ever indicate which trainings are repeated year after year without knowing the effectiveness. Learning and Organizational Development Managers looking for results need to invest substantially into pre-training and post-training not only on the event in achieving desired results. Goldstein and Ford [43], Salas and Canon-Bowers [44] and Tung and Chun [19] have emphasized on the importance of training need assessment to increase training effectiveness repeatedly.

To avoid errors in selecting training courses and gaining good return it is necessary for organizations to go through TNA writes Elbadri [45]

\section{Conclusion}

Peterson [46] states that organizations typical investment mostly towards training event rather than on pre-work of training and post training evaluation. He elaborates that training managers invest only $10 \%$ on pre-work which includes training needs, training design and training development; approximately $85 \%$ of the budget is invested on training delivery and mere $5 \%$ is spent on training evaluation. With this $85 \%$ investment organization only reap $24 \%$ learning effectiveness.

The best approach for effective outcome of training for organization; especially in third world countries for TNA approach is totally neglected. Executives expecting to reap greater results need to invest into training need analysis giving L\&OD a chance to target training as per the needs. Kumpikaite expresses his concerns in his research regarding training and thoughts of the organizations on Training investment. In Kumpikaite research he writes that only $17.1 \%$ organizations under investigation saw training investment as a competitive advantage. Approximately $34.3 \%$ of the companies still perceive training and development a waste of time. $59.4 \%$ of the companies still feel that on the job learning is more important than formal trainings.

Time and again the training does not receive much importance as an investment which might provide greater returns. Companies investing in to trainings needs to focus more attention to the TNA, TNA based Design of training and Evaluation to be able to better understand the performance of L\&OD and its contributions. We are expecting greater results without investing much into the head and the due systematic processes.

\section{References}

1. Brinkerhoff RO (2006) Increasing impact of training investments: an evaluation strategy for building organizational learning capability. Industrial and Commercial Training 38: 302-307.

2. Mooney T, Brinkerhoff RO (2008) Courageous Training: Bold Actions for Business Results. Berret-Koehler Publishers.

3. Fitzpatrick $R$ (2001) The strange case of the transfer of training estimates. The Industrial Organizational Psychologist 39: 18-19.

4. Som HBM, Nam RYT (2011) Organizational-Level Training Need Analysis (TNA): Findings from the Top 1000 Companies in Malaysia. Journal of Global Business Management.

5. Robinson DG (2008) Learning Transfer, ASTD 2008. International Conference and Exposition, CA: ASTD.
6. Arthur W Jr, Bennett W Jr, Edens PS, Bell ST (2003) Effectiveness of training in organizations: A meta-analysis of design and evaluation features. Journal of Applied Psychology 88: 234-245.

7. Agnaia AA (1996) Assessment of management training needs and selection for training: the case of Libyan companies. International Journal of Manpower 17: $31-51$

8. Phillips JJ (2014) Confronting CEO Expectations About the Value of Learning

9. Gupta K, Sleezer CM, Russ-Eft DF (2007) A practical Guide to Needs Assessment (2ndedn), John Wiley and Sons Inc.

10. Bersin J (2013) How Corporate Learning Drives Competitive Advantage. Forbes: Leadership.

11. Taylor PJ, O’Driscoll MP (1998) A New Integrated Framework for Training Need Analysis. Human Resource Management Journal 8: 29-50.

12. Miller JA, Osinski DM (2002) Training and Development Committee. Training Need Assessment: A Critical Study.

13. Dakiya S, Jha A (2011) International Journal of Information Technology and Knowledge Management 4: 263-267.

14. Skillnets (2013) Training Network Program Funding to Grow Skills and Sustain Jobs. Training Need Analysis Guide.

15. Goldstein IL (1991) Training in work organizations. In: Dunnette MD, Hough LM (eds). Handbook of industrial and organizational psychology, Palo Alto, CA US: Consulting Psychologists Press, pp: 507-619.

16. Eramus BJ, Schenk H, Swanepoel BJ (2014) South African Human Resource Management Theory and Practice. Cape Town: Juta.

17. Molenda MJ, Pershing JA, Reigloth CM (1996) Designing Instructional Systems. In RL Craig The ASTD Training and Development Handbook (4thedn), McGraw Hill, New York, pp: 266-293.

18. Van Dyk PS, Nel PS, Leodolff PVZ, Hassblock GD (1997) Training Management Johannesburg, Thompson.

19. Tung-Chun $\mathrm{H}$ (2001) The Relation of Training Practices and Organizational Performance in Small and Medium Size Enterprises. Education plus Training 43: $437-444$.

20. Kirkpatrick JD, Kirkpatrick WK (2016) Four Levels of Training Evaluation. ATD Press: VA.

21. Ellis R (2015) Popular Learning Evaluation Models: An Infographics Association of Talent Development.

22. Kirkpatrick DL (1998) Evaluating Training Programs: The Four Levels (2ndedn), Berret-Koehler Publisher Inc.

23. Cosh A, Duncan J, Hughes A (1998) Investment in Training and Small Firm Growth and Survival: An empirical analysis for the UK 1987-1995. VOCED plus NCVER's international tertiary education research database.

24. McClelland SD (2002) A Training Need Assessments for the United Way of Dunn County Wisconsin. University of Wisconsin-Stout, Madison.

25. Ghufli AHB (2014) Training Needs Analysis: An empirical Study of the Abu Dhabi Police. Brunel Business School, London, United Kingdom.

26. Cohen DJ (1990) What motivates Trainees. Training and Development Journal 44: $91-93$

27. Clark CS, Dobbins GH, Ladd RT (1993) Exploratory field study of training motivation: Influence of involvement, credibility, and transfer climate. Group \& Organization Management 18: 292-307

28. Facteau JD, Dobbins GH, Russell JFA, Ladd RT, Kudisch JD (1995) The influence of general perceptions of the training environment on pretraining motivation and perceived training transfer. Journal of Management 21: 1-25.

29. Farr JL, Middlebrooks CL (1990) Enhancing motivation to participate in professional development. Willis SL, Dubin SS (Eds) The Jossey-Bass Higher Education Series and The Jossey-Bass Management Series. Maintaining professional competence: Approaches to career enhancement vitality, and success throughout a work life, San Francisco, CA, US: Jossey-Bass, pp: 195-213.

30. Chen ZX, Tsui AS, Farh JL (2002) Loyalty to Supervisor vs Organizationa Commitment: Relationship to Employee Performance in China. Journal of Occupational and Organizational Psychology 75: 339-351. 
Citation: Mohammed H (2018) There is No Tail without the Head: The Missing Pieces, the Alignment and the Training Returns through Training Need Assessment. J Entrepren Organiz Manag 7: 236. doi: 10.4172/2169-026X.1000236

Page 7 of 7

31. Tesluk PE, Farr JL, Mathieu JE, Vance RJ (1995) Generalization of Employee Involvement Training to the Job Setting: Individual and Situational Effects. Personnel Psychology 48: 607-632.

32. Winters D, Latham GP (1996) The effect of Learning vs Outcome Goals on simple versus a complex Task. Group and Organization Management 21: 236-250.

33. Steven CK, Gist ME (1997) Effects of Self-Efficacy and Goal-Orientation Training on Negotiation Skills Maintenance: What are the Mechanisms? Personnel Psychology 50: 955-978.

34. McGriff SJ (2000) Instructional Systems. College of Education, Penn State University.

35. Branson RK, Rayner GT, Cox JL, Furman JP, King FJ (1975) Interservice Procedures for Instructional Systems Development. Phase 4 and 5, Implement and Control. Florida State Univ Tallahassee Center For Educational Technology.

36. Treser M (2015) Getting to Know ADDIE: Part 1 - Analysis.

37. Rossett A (1987) Techniques in Training and Performance Development Series. Business \& Economics.

38. Bowen RS (2017) Understanding by Design. Vanderbilt University Center for Teaching.
39. https://www. wiley.com/en-us/The+Trainer\%27s+Handbook\%2C+2nd+Edition-p9780787985226 .

40. Felder RM, Brent R (2003) Designing and Teaching Courses to Satisfy the ABET Engineering Criteria. Journal of Engineering Education 92: 7-25.

41. Bloom BS (1984) Taxonomy of Educational Objectives Cognitive Domain Longman, New York.

42. Felder RM, Brent R (1999) How to Improve Teaching Quality. Quality Management Journal 6: 9-21.

43. Goldstein IL, Ford JK (2002) Training in organizations: Needs assessment, development, and evaluation (4thedn), Belmont, CA, US: Wadsworth/Thomson Learning.

44. Salas E, Canon Bowers JA (2001) The Science of Training: A Decade of Progress. Annual Review Psychology 52: 471-499.

45. Elbadri ANA (2001) Training practices of Polish companies: an appraisal and agenda for improvement. Journal of European Industrial Training 25: 69-79.

46. Peterson B (2004) Invest in Follow-up, Increase the Learning Effect. Dynamo. 